\title{
The effect of postoperative medical treatment on left ventricular mass regression after aortic valve replacement
}

\author{
Meghana R. K. Helder, MD, ${ }^{a}$ Murat Ugur, MD, ${ }^{a}$ Joseph E. Bavaria, MD, ${ }^{\mathrm{b}}$ Vibhu R. Kshettry, MD, ${ }^{\circ}$ \\ Mark A. Groh, MD, ${ }^{\mathrm{d}}$ Michael R. Petracek, MD, ${ }^{\mathrm{e}}$ Kent W. Jones, MD,${ }^{\mathrm{f}}$ Rakesh M. Suri, MD, ${ }^{\mathrm{a}}$ and \\ Hartzell V. Schaff, MD ${ }^{\mathrm{a}}$
}

\begin{abstract}
Objective: The study objective was to analyze factors associated with left ventricular mass regression in patients undergoing aortic valve replacement with a newer bioprosthesis, the Trifecta valve pericardial bioprosthesis ( $\mathrm{St}$ Jude Medical Inc, St Paul, Minn).
\end{abstract}

\begin{abstract}
Methods: A total of 444 patients underwent aortic valve replacement with the Trifecta bioprosthesis from 2007 to 2009 at 6 US institutions. The clinical and echocardiographic data of 200 of these patients who had left ventricular hypertrophy and follow-up studies 1 year postoperatively were reviewed and compared to analyze factors affecting left ventricular mass regression.
\end{abstract}

\begin{abstract}
Results: Mean (standard deviation) age of the 200 study patients was 73 (9) years, $66 \%$ were men, and $92 \%$ had pure or predominant aortic valve stenosis. Complete left ventricular mass regression was observed in 102 patients $(51 \%)$ by 1 year postoperatively. In univariate analysis, male sex, implantation of larger valves, larger left ventricular end-diastolic volume, and beta-blocker or calcium-channel blocker treatment at dismissal were significantly associated with complete mass regression. In the multivariate model, odds ratios $(95 \%$ confidence intervals) indicated that male sex (3.38 [1.39-8.26]) and beta-blocker or calcium-channel blocker treatment at dismissal (3.41 [1.40-8.34]) were associated with increased probability of complete left ventricular mass regression. Patients with higher preoperative systolic blood pressure were less likely to have complete left ventricular mass regression (0.98 [0.97-0.99]).
\end{abstract}

Conclusions: Among patients with left ventricular hypertrophy, postoperative treatment with beta-blockers or calcium-channel blockers may enhance mass regression. This highlights the need for close medical follow-up after operation. Labeled valve size was not predictive of left ventricular mass regression. (J Thorac Cardiovasc Surg 2015;149:781-6)

See related commentary on pages 787-8.

Left ventricular (LV) hypertrophy negatively influences postoperative survival after aortic valve replacement (AVR). ${ }^{1}$ The extent of $\mathrm{LV}$ mass regression after AVR

From the Division of Cardiovascular Surgery, ${ }^{a}$ Mayo Clinic, Rochester, Minn; Division of Cardiovascular Surgery, ${ }^{\mathrm{b}}$ Hospital of the University of Pennsylvania, Philadelphia, Pa; Minneapolis Heart Institute, ${ }^{\mathrm{c}}$ Minneapolis, Minn; Cardiovascular and Thoracic Surgery, ${ }^{\mathrm{d}}$ Mission Health and Hospitals, Asheville, NC; Department of Cardiac Surgery, ${ }^{\mathrm{e}}$ Vanderbilt Medical Center, Nashville, Tenn; and Intermountain Medical Center, ${ }^{\mathrm{f}}$ Salt Lake City, Utah.

Disclosures: Mark A. Groh reports consulting fees for St. Jude Medical. Rakesh M. Suri reports consulting fees from the Sorin-Perceval trial patent applications, PI for the PErceval trial, and co-PI for the Abbott COAPT trial. All other authors have nothing to disclose with regard to commercial support.

Mayo Clinic does not endorse the products mentioned in this article.

Presented at The American Association for Thoracic Surgery Cardiovascular Valve Symposium, Harbiye, Istanbul, Turkey, September 4-6, 2014.

Received for publication July 25, 2014; revisions received Sept 25, 2014; accepted for publication Oct 4, 2014; available ahead of print Nov 27, 2014.

Address for reprints: Hartzell V. Schaff, MD, Division of Cardiovascular Surgery, Mayo Clinic, 200 First St SW, Rochester, MN 55905 (E-mail: schaff@mayo.edu). $0022-5223 / \$ 36.00$

Copyright (c) 2015 by The American Association for Thoracic Surgery http://dx.doi.org/10.1016/j.jtcvs.2014.10.034 appears to be dependent on both transvalvular pressure gradients $^{2,3}$ and aortic valve (AV) area after replacement. ${ }^{4}$

Newer bioprostheses may have better hemodynamic profiles than older ones, which may lead to more complete LV mass regression in patients undergoing AVR. As reported by Wendt and colleagues, ${ }^{5}$ AVR with bovine pericardial prostheses results in relatively low transvalvular gradients and increased AV areas. The Trifecta valve pericardial bioprosthesis (St Jude Medical Inc, St Paul, Minn) was implanted in 1014 patients between 2007 and 2009 at 31 centers worldwide. The initial results were promising; for patients with 19- and 29-mm prostheses, average mean gradients at hospital dismissal were 9.3 and $4.1 \mathrm{~mm} \mathrm{Hg}$, respectively, and effective orifice area (EOA) ranged from 1.58 to $2.50 \mathrm{~cm}^{2}$. In the current study, we analyzed determinants of LV mass regression in patients undergoing AVR with this new pericardial bioprosthesis.

\section{MATERIALS AND METHODS}

To fulfill regulatory requirements of clinically evaluating the Trifecta valve, patients from 6 centers with the highest enrollment (Mayo Clinic, Rochester, Minn; Hospital of the University of Pennsylvania, Philadelphia, $\mathrm{Pa}$; Minneapolis Heart Institute, Minneapolis, Minn; Mission Health and Hospitals, Asheville, NC; Vanderbilt Medical Center, Nashville, Tenn; and Intermountain Medical Center, Salt Lake City, Utah) were chosen 


$$
\begin{aligned}
& \text { Abbreviations and Acronyms } \\
& \text { AV }=\text { aortic valve } \\
& \text { AVR }=\text { aortic valve replacement } \\
& \text { CI }=\text { confidence interval } \\
& \text { EOA }=\text { effective orifice area } \\
& \text { LV }=\text { left ventricular } \\
& \mathrm{OR}=\text { odds ratio } \\
& \mathrm{SD}=\text { standard deviation }
\end{aligned}
$$

$(n=444)$ as a subset of patients from the 31 centers in the initial investigation device exemption study $(\mathrm{n}=1014)$ for long-term follow-up. In addition to initial consent to participate in the study, all subjects signed consent for follow-up visits, clinical evaluation, and echocardiography. Institutional review board approval was obtained at each participating site. Details of bioprosthetic AV implantation and definition of adverse events have been published. ${ }^{6}$ Briefly, early adverse events were those that occurred before 30 days postimplantation, and late events occurred after 30 days.

For the entire group of patients, we examined clinical data to determine hemodynamic outcomes, valve gradients, and survival during a follow-up period of 5 years. We also analyzed determinants of LV mass regression. Among the 444 available patients, 405 had sufficient echocardiographic information to calculate LV mass, as follows:

$$
\begin{aligned}
\mathrm{LV} \text { mass }(\text { in grams }) & =(0.832 \times 1.04[\text { interventricular septal thickness } \\
& +\mathrm{LV} \text { end }- \text { diastolic dimension (in millimeters) } \\
& +\mathrm{LV} \text { posterior wall thickness }\}^{3} \\
& \left.\left.-(\mathrm{LV} \text { end }- \text { diastolic dimension })^{3}\right]\right) / 1000+0.6 \mathrm{~g} .{ }^{7}
\end{aligned}
$$

LV mass index (in grams/meters squared) was calculated by dividing LV mass by body surface area. LV hypertrophy was defined as an LV mass index greater than $95 \mathrm{~g} / \mathrm{m}^{2}$ for women and greater than $115 \mathrm{~g} / \mathrm{m}^{2}$ for men. ${ }^{8}$ Postoperative predismissal echocardiograms and all subsequent echocardiograms were read in a central core laboratory, and we used data from the predismissal echocardiogram for baseline data on LV hypertrophy.

Continuous variables are presented as mean (standard deviation [SD]), and categoric variables are presented as number of patients (percentage). All $P$ values for comparisons between groups are based on the 2-sample $t$ test, chi-square test, or Fisher exact test. No adjustments for multiple comparisons were made. We analyzed LV mass regression by 2 methods. First, we categorized patients with LV hypertrophy as having complete or incomplete regression of hypertrophy 1 year postoperatively on the basis of the cutoff values given earlier. In a second analysis, we used the absolute change in LV hypertrophy from the initial echocardiogram to the 1-year time point. For both end points, we performed univariate and multivariate analyses on clinical variables. All variables with a $P$ value less than .2 in the univariate analysis were included in the multivariate analysis. In the multivariate analysis, $P$ $<.05$ was considered significant. The Kaplan-Meier method was used to estimate survival for patients who had complete LV mass regression compared with those who did not. However, because data at 1 year were required to compose the groups, only deaths after 1 year were included. St Jude Medical Inc was involved in the collection of data and provided statistical support.

\section{RESULTS}

The mean (SD) age of all 444 patients was 73.5 (8.9) years. Demographics and preoperative findings for these patients are detailed in Table 1. Implanted AV sizes ranged from 19 to 29 $\mathrm{mm}$, with $31.5 \%$ of patients $(\mathrm{n}=140)$ receiving a $23-\mathrm{mm}$ valve. Total duration of follow-up was 1333.5 patient-years.

\section{Hemodynamic Performance}

The mean (SD) initial AV gradient was 7.4 (3.3) $\mathrm{mm} \mathrm{Hg}$. The gradient increased slightly to $9.4(4.6) \mathrm{mm} \mathrm{Hg}$ at 3 years and $9.8(5.0) \mathrm{mm} \mathrm{Hg}$ at 5 years. Mean (SD) initial EOA was $1.95(0.37) \mathrm{cm}^{2}$, compared with $1.60(0.37) \mathrm{cm}^{2}$ at 3 years and $1.58(0.37) \mathrm{cm}^{2}$ at 5 years postoperatively. Initial indexed EOA was $0.98 \quad(0.18) \quad \mathrm{cm}^{2} / \mathrm{m}^{2}$, compared with $0.80(0.17) \mathrm{cm}^{2} / \mathrm{m}^{2}$ at 3 years and 0.80 $(0.18) \mathrm{cm}^{2} / \mathrm{m}^{2}$ at 5 years postoperatively.

Most patients $(n=441,99.3 \%)$ had no or trivial aortic insufficiency at dismissal. At 3 years (258 patients at risk), $66.3 \%$ of patients $(\mathrm{n}=171)$ had no aortic regurgitation, $19.8 \%$ of patients $(\mathrm{n}=51)$ had trivial regurgitation, and $11.2 \%$ of patients $(n=29)$ had mild regurgitation. At 5 years (34 patients at risk), $50 \%$ of patients $(\mathrm{n}=17)$ had no regurgitation, $29.4 \%$ of patients $(\mathrm{n}=10)$ had trivial regurgitation, $14.7 \%$ of patients $(n=5)$ had mild regurgitation, and $5.9 \%$ of patients $(n=2)$ had moderate regurgitation.

\section{Adverse Events and Survival Among All Patients}

Adverse events after AVR are shown in Table 2. At 3 years, cumulative freedom from embolism, endocarditis, nonstructural dysfunction, and structural valve deterioration was $95.4 \%, 99.1 \%, 99.2 \%$, and $99.7 \%$, respectively. The same measures at 5 years (30 patients at risk) were $94.9 \%, 99.1 \%, 99.2 \%$, and $99.7 \%$, respectively. Seven patients required reoperation for replacement of the prosthesis; 1 of these events occurred early and was due to partial obstruction of the left main coronary artery. The 6 late explantations were due to endocarditis $(n=2)$, structural valve deterioration $(\mathrm{n}=1)$, and nonstructural dysfunction $(\mathrm{n}=3)$. Freedom from AV reoperation 3 years postoperatively was $98.6 \%$. At 3 years, cumulative freedom from overall mortality was $93.2 \%$, and freedom from valve-related mortality was $99.5 \%$. No valve thrombosis, minor paravalvular leak, or clinically significant hemolysis occurred.

\section{Left Ventricular Mass Regression}

The average initial LV mass index for all 405 patients with data available (including those who did not have LV hypertrophy) was $113.6 \mathrm{~g} / \mathrm{m}^{2}$. By 1 year postoperatively, the LV mass index had decreased to $102.6 \mathrm{~g} / \mathrm{m}^{2}$ with little further decrease during the subsequent 4 years (5-year average, $101.7 \mathrm{~g} / \mathrm{m}^{2}$ ). Thus, the 1-year follow-up time point was chosen for our analysis to identify determinants of LV mass regression.

A total of 200 patients who had LV hypertrophy at the time of operation and sufficient echocardiographic data to allow determination of LV mass index 1 year postoperatively were analyzed further. These patients had a mean (SD) age of 73 (9) years, and $132(66 \%)$ were men. Ninety-two percent $(n=184)$ had pure or predominant AV stenosis.

We compared the patient subsets of approximately $50 \%$ each who had complete $(n=102)$ and incomplete $(n=98)$ 
TABLE 1. Demographics and preoperative findings

\begin{tabular}{lc}
\hline \multicolumn{1}{c}{ Variable } & Value* $(\mathbf{N}=\mathbf{4 4 4})$ \\
\hline Age at implant, y & $73.5(8.9)$ \\
Men & $299(67.3)$ \\
BMI, kg/m ${ }^{2}$ & $29.5(5.2)$ \\
Body surface area, ${ }^{2}$ & $2(0.2)$ \\
History of smoking & $249(56.1)$ \\
Diagnosis of hypertension & $364(82.0)$ \\
History of diabetes mellitus & $109(24.5)$ \\
Atrial fibrillation/flutter & $39(8.8)$ \\
History of CHF & $154(34.7)$ \\
History of PVD & $53(11.9)$ \\
History of CVD & $24(5.4)$ \\
NYHA class & \\
I & $26(5.9)$ \\
II & $190(42.8)$ \\
III & $209(47.1)$ \\
IV & $19(4.3)$ \\
Previous cardiovascular surgery/procedure & $128(28.8)$ \\
Previous AVR & $4(0.9)$ \\
Previous CABG & $27(6.1)$ \\
History of coronary artery disease & $274(61.7)$ \\
Aortic crossclamp time, min & $84.4(37.1)$ \\
For isolated AVR & $64.4(27.8)$ \\
Cardiopulmonary bypass time, min & $114.3(51.6)$ \\
For isolated AVR & $87.6(40.2)$ \\
\hline$A V R$, Aortic valve replacement; $B M I$, body mass index; $C A B G$, & coronary artery \\
bypass grafting; $C H F$, congestive heart failure; $C V D$, cardiovascular disease; & \\
$N Y H A$, New York Heart Association; $P V D$, peripheral vascular disease. $*$ Values are \\
mean (SD) or number of patients (\%).
\end{tabular}

regression of LV hypertrophy. Multiple clinical variables were analyzed as predictors of complete LV mass regression (Table 3). In this unadjusted comparison, male sex $(P<.001)$, larger implanted valve sizes $(P=.01)$, larger

TABLE 2. Early and late adverse events

\begin{tabular}{lccc}
\hline & $\begin{array}{c}\text { Early events, } \\
\text { no. }(\%) \\
\text { Adverse event }\end{array}$ & $\begin{array}{c}\text { Late } \\
\mathbf{N}=\mathbf{4 4 4})\end{array}$ & $\begin{array}{c}\text { Linearized } \\
\text { rate, per 100 }\end{array}$ \\
patient-y
\end{tabular}

PV, Paravalvular; RIND, reversible ischemic neurologic deficit; TIA, transient ischemic attack.
TABLE 3. Clinical features by mass regression $(n=200)$

\begin{tabular}{|c|c|c|c|}
\hline \multirow[b]{2}{*}{ Variable } & \multicolumn{2}{|c|}{ Mass regression* } & \multirow[b]{2}{*}{$P$ value } \\
\hline & $\begin{array}{l}\text { Complete } \\
(\mathbf{n}=\mathbf{1 0 2})\end{array}$ & $\begin{array}{c}\text { Incomplete } \\
(\mathbf{n}=98)\end{array}$ & \\
\hline Men & $81(79.4)$ & $51(52.0)$ & $<.001$ \\
\hline Age, y & $72.3(9.9)$ & $74.7(8.8)$ & .07 \\
\hline $\begin{array}{l}\text { Preoperative NYHA class III } \\
\text { or IV }\end{array}$ & $47(46.1)$ & $49(50.0)$ & .69 \\
\hline Valve size category & & & .01 \\
\hline Small (19 or $21 \mathrm{~mm})$ & $28(27.5)$ & $47(48.0)$ & \\
\hline Medium (23 or $25 \mathrm{~mm}$ ) & $62(60.8)$ & $44(44.9)$ & \\
\hline Large (27 or $29 \mathrm{~mm})$ & $12(11.8)$ & $7(7.1)$ & \\
\hline Ejection fraction, \% & $57.9(10.8)$ & $58.4(11.4)$ & .76 \\
\hline Initial mean gradient, $\mathrm{mm} \mathrm{Hg}$ & $7.2(3.1)$ & $7.9(3.8)$ & 20 \\
\hline Initial LV mass index, $\mathrm{g} / \mathrm{m}^{2}$ & $133.0(23.8)$ & $134.0(24.7)$ & .76 \\
\hline Indexed EOA, $\mathrm{cm}^{2} / \mathrm{m}^{2}$ & $0.98(0.19)$ & $0.96(0.19)$ & .38 \\
\hline Discharge EOAi category & $(\mathrm{n}=100)$ & $(\mathrm{n}=94)$ & .53 \\
\hline$<0.65$ & $3(3.0)$ & $3(3.2)$ & \\
\hline $0.65-0.85$ & $22(22.0)$ & 27 (28.7) & \\
\hline$>0.85$ & $75(75.0)$ & $64(68.1)$ & \\
\hline LV end-diastolic volume, $\mathrm{mL}$ & $98.7(33.1)$ & $88.6(28.8)$ & .02 \\
\hline LV end-systolic volume, $\mathrm{mL}$ & $43.7(24.9)$ & $38.1(19.9)$ & .08 \\
\hline Concomitant CABG & $31(30.4)$ & $36(36.7)$ & .34 \\
\hline History of hypertension & $82(80.4)$ & $81(82.7)$ & .68 \\
\hline \multicolumn{4}{|l|}{ Systolic blood pressure, $\mathrm{mm} \mathrm{Hg}$} \\
\hline Preoperative & $131.9(18.5)$ & $138.3(21.4)$ & .02 \\
\hline At $1 \mathrm{y}$ & $133.4(16.0)$ & $136.3(19.4)$ & .26 \\
\hline \multicolumn{4}{|l|}{ Taking BB or CCB } \\
\hline At dismissal & $92(90.2)$ & $78(79.6)$ & .04 \\
\hline At $1 \mathrm{y}$ & $82(80.4)$ & $80(81.6)$ & .82 \\
\hline $\begin{array}{l}\text { Preoperative body surface } \\
\text { area, } \mathrm{m}^{2}\end{array}$ & $2.0(0.2)$ & $1.9(0.2)$ & .001 \\
\hline
\end{tabular}

$\overline{B B}$, Beta-blocker; $C A B G$, coronary artery bypass grafting; $C C B$, calcium-channel blocker; $E O A$, effective orifice area; $E O A i$, indexed effective orifice area; $L V$, left ventricular; NYHA, New York Heart Association. *Values are mean (SD) or number of patients (\%).

LV end-diastolic volume $(P=.02)$, lower preoperative systolic blood pressure $(P=.02)$, treatment with beta-blockers or calcium-channel blockers at dismissal

TABLE 4. Multivariate analysis

\begin{tabular}{llc}
\hline \multicolumn{1}{c}{ Variable } & $\begin{array}{c}\text { Odds ratio } \\
(\mathbf{9 5} \% \mathbf{C I})\end{array}$ & $\boldsymbol{P}$ value \\
\hline Men & $3.38(1.39-8.26)$ & .007 \\
Age, $\mathrm{y}^{*}$ & $0.98(0.94-1.01)$ & .21 \\
Valve size & & .96 \\
$\quad$ Small vs large & $0.83(0.20-3.39)$ & \\
$\quad$ Medium vs large & $0.84(0.26-2.72)$ & \\
Discharge LV end-diastolic volume, $\mathrm{mL}^{*}$ & $1.00(0.97-1.02)$ & .71 \\
Discharge LV end-systolic volume, $\mathrm{mL}^{*}$ & $1.00(0.97-1.03)$ & .85 \\
Higher preoperative systolic blood pressure* & $0.98(0.97-0.99)$ & .04 \\
Preoperative BSA, ${ }^{2} *$ & $2.18(0.35-13.61)$ & .40 \\
Taking CCB at 1 y & $1.35(0.64-2.83)$ & .43 \\
Taking BB or CCB at discharge & $3.41(1.40-8.34)$ & .007 \\
\hline$B B$, Beta-blocker; $B S A$, body surface area; $C C B$, calcium-channel blocker; $C I$, confi- \\
dence interval; $L V$, left ventricular. ${ }^{*}$ Calculated as a continuous variable. &
\end{tabular}




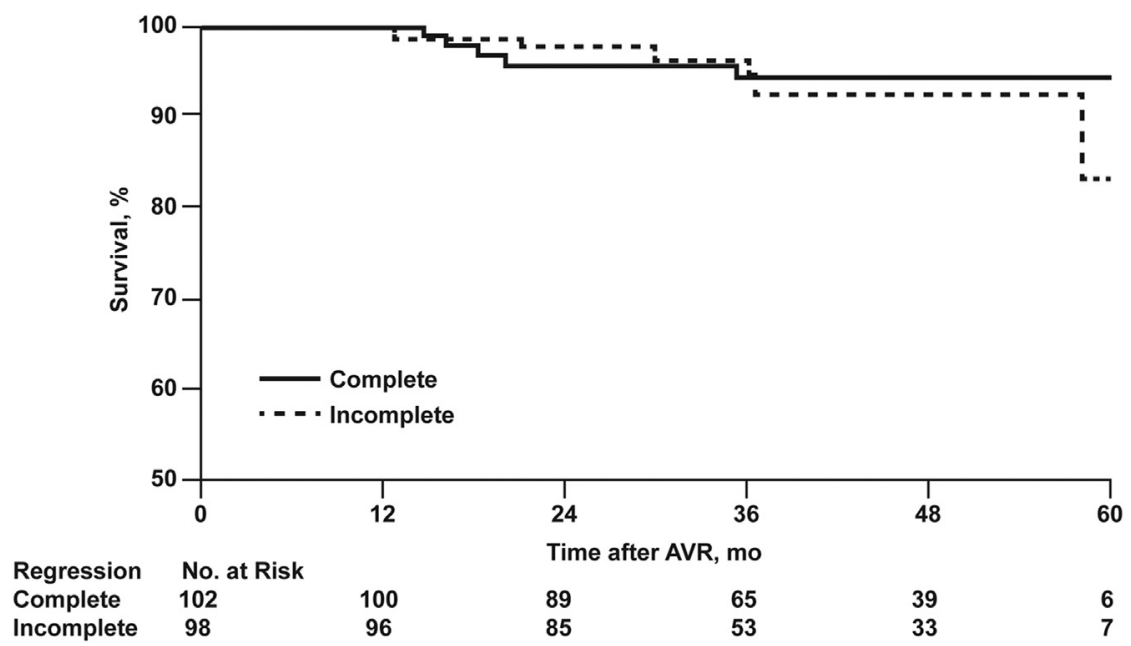

FIGURE 1. Kaplan-Meier survival curves. Probability of survival for patients who had complete $(\mathrm{n}=102)$ and incomplete $(\mathrm{n}=98)$ regression of $\mathrm{LV}$ hypertrophy after AVR. At 5 years, probability of survival was $94.5 \%$ for patients with complete regression and $83.5 \%$ for patients with incomplete regression $(P=.67)$. AVR, Aortic valve replacement.

$(P=.04)$, and higher preoperative body surface area $(P=.001)$ were all associated with complete mass regression.

In the multivariate analysis (Table 4), male sex (odds ratio $[\mathrm{OR}], 3.38$; 95\% confidence interval $[\mathrm{CI}], 1.39-8.26$ ) and treatment with beta-blockers or calcium-channel blockers at dismissal (OR, 3.41; 95\% CI, 1.40-8.34) were independently associated with increased probability of complete LV mass regression. Patients with higher preoperative systolic blood pressure were less likely to have complete LV mass regression (OR, $0.98 ; 95 \% \mathrm{CI}$, 0.97-0.99). Valve size was not predictive of complete LV mass regression in the multivariate model (OR, 0.83; 95\% CI, 0.20-3.39).

In a second analysis, LV mass regression was expressed as change in LV mass from baseline. On univariate analysis, male sex, younger age, larger initial LV mass index, lower initial ejection fraction, larger initial LV end-diastolic and end-systolic volumes, higher preoperative systolic blood pressure, and smaller preoperative body surface area were associated with greater $\mathrm{LV}$ mass regression $(P<.05)$ (data not shown). When these and other variables with a $P$ value less than .2 were included in a multivariate analysis, independent determinants of $\mathrm{LV}$ mass regression were larger initial LV mass index (parameter estimate, -0.75 ; $95 \% \mathrm{CI},-0.88$ to 0.61 ) and higher preoperative systolic blood pressure (parameter estimate, 0.23 ; $95 \%$ CI, 0.07 0.40). Thus, the final model suggests that a higher initial LV mass index results in a greater decrease in LV mass and that higher preoperative systolic blood pressure is associated with less LV mass reduction.

We analyzed blood pressure at follow-up intervals and found no difference in mean systolic pressure in patients who had complete versus incomplete LV mass regression.
Mean (SD) values for the 2 groups, respectively, were 133 (16) versus $136(19) \mathrm{mm} \mathrm{Hg}$ at 1 year $(P=.26), 132$ (16) versus $133(16) \mathrm{mm} \mathrm{Hg}$ at 3 years $(P=.73)$, and $136(20)$ versus $128(20) \mathrm{mm} \mathrm{Hg}$ at 5 years $(P=.30)$. Also, there was no difference in symptomatic status, as reflected by New York Heart Association class, between patients with complete regression and patients with incomplete regression. The percentage of patients with class III or IV status for the 2 groups, respectively, was $0 \%$ versus $1.1 \%$ at 1 year $(P=.49), 0 \%$ versus $0 \%$ at 3 years, and $6.3 \%$ versus $0 \%$ at 5 years $(P>.99)$. Survival at 5 years was similar among patients with complete or incomplete LV mass regression $(P=.67)$ (Figure 1$)$.

\section{DISCUSSION}

An important finding in this study was the benefit of treatment with beta-blockers and calcium-channel blockers in LV mass regression after AVR. Patients who at dismissal were taking 1 or both of these medications were more likely to have complete LV mass regression compared with untreated patients. To our knowledge, this effect of medical treatment on regression of LV hypertrophy after AVR has not been reported. Tomoeda and colleagues ${ }^{9}$ found that prevention of postoperative hypertension in select patients without $\mathrm{LV}$ dilatation and indexed EOA greater than $0.77 \mathrm{~cm}^{2} / \mathrm{m}^{2}$ could prevent postoperative LV hypertrophy. However, we believe that the effect of beta-blockers extends beyond treatment of hypertension. Beta-blockade has been used in patients with heart failure for approximately 2 decades to prevent maladaptive remodeling of the $\mathrm{LV}$ and to promote regression of LV hypertrophy. Indeed, beta-blockers have been shown to improve LV function in patients with systolic heart failure. ${ }^{10}$ The mechanism may be related to improved cardiac calcium release channel function. ${ }^{11}$ 
Calcium-channel blocker use should theoretically decrease afterload and help with diastolic function. ${ }^{12}$ However, as studies in heart failure have shown, ${ }^{13,14}$ other risks may be associated with calcium-channel blockers that should be analyzed before prescribing them for LV hypertrophy associated with aortic stenosis.

Another important finding in our series was that most of the regression of LV mass occurred during the first postoperative year. This is similar to the findings of Tomoeda and colleagues, ${ }^{9}$ who studied 48 consecutive patients undergoing AVR for aortic stenosis in whom the average LV mass index was $250 \mathrm{~g} / \mathrm{m}^{2}$. In their patients, LV mass was decreased to a plateau of $150 \mathrm{~g} / \mathrm{m}^{2}$ by 1 year postoperatively. Therefore, it seems likely that LV hypertrophy after 1 year in patients with normally functioning AV prostheses is due to other cardiovascular diseases, such as systemic arterial hypertension.

We analyzed LV mass regression by 2 different methods, using LV mass as a dichotomous or continuous variable. Expressing LV mass regression as a dichotomous variable, complete or incomplete, may be more relevant clinically than using the change in LV mass. For example, in a patient with a greatly hypertrophied LV, mass may regress substantially, resulting in a sizeable absolute reduction in LV mass, but hypertrophy could still remain and the patient may have residual symptoms due to diastolic dysfunction. In our multivariate analysis using LV mass regression as a dichotomous variable, the factors contributing most to complete regression of LV mass were male sex, lower preoperative systolic blood pressure, and treatment with beta-blockers or calcium-channel blockers at dismissal. Prosthesispatient mismatch and preoperative LV hypertrophy were not factors contributing to complete LV mass regression.

In our study, men were more likely than women to achieve complete LV mass regression. This finding was similar to results reported by Del Rizzo and colleagues. ${ }^{15}$ In contrast, Hanayama and colleagues ${ }^{16}$ and Beach and colleagues ${ }^{17}$ suggested that LV mass regression after AVR for AV disease is more complete in women than in men. In our series, definition of LV hypertrophy was stratified by sex, ${ }^{7}$ which may explain some differences between our findings and those in previous reports.

In contrast to previous publications, ${ }^{16,17}$ the current study found that lower preoperative systolic blood pressure was associated with complete LV mass regression. Some of the discrepancy in the findings may arise from definitions of hypertension. In univariate analysis, we examined the relationship between complete mass regression and multiple definitions of hypertension, including diagnosis of hypertension preoperatively, treatment of hypertension at dismissal, diagnosis of hypertension at 1 year postoperatively, and systolic blood pressure preoperatively and at 1 year. Among these variables, only preoperative systolic blood pressure as a continuous variable was found to be associated significantly with complete mass regression. The variables used in other studies ${ }^{17}$ were based on patient-reported diagnosis, which potentially introduces error in interpretation and medical recording. Quantitative variables are more likely to be reliable than diagnostic labels.

Our patient cohort is representative of elderly patients who have senescent AV stenosis, and these patients typically have less LV hypertrophy than younger patients with congenitally bicuspid or unicuspid AV disease. In this study, only $55 \%$ of patients had LV hypertrophy at the time of AVR, and this prevalence of LV hypertrophy in patients undergoing AVR for aortic stenosis is somewhat higher than other investigators have described. Hanayama and colleagues ${ }^{16}$ reported that only $25 \%$ of patients with aortic stenosis had LV hypertrophy at the time of operation. However, these authors did not use a sex-based definition of LV hypertrophy and thus may have underestimated the frequency of hypertrophy in women.

LV hypertrophy at the time of AVR confers a poor prognosis postoperatively. In the experience of Mihaljevic and colleagues, ${ }^{18}$ survival at 10 years after AVR in patients with LV hypertrophy was $50 \%$, compared with $70 \%$ for patients without LV hypertrophy $(P=.03)$. Therefore, it is reasonable to hypothesize that complete regression of LV hypertrophy after AVR might improve late survival, but this has not been demonstrated conclusively. Gaudino and colleagues ${ }^{19}$ found that the extent of LV mass regression did not affect postoperative survival after AVR. Our study also shows no survival benefit among patients who achieved complete LV mass regression compared with those who had incomplete LV mass regression. However, it is clear that regression of LV mass is closely associated with increased LV contractility postoperatively, ${ }^{20}$ which would be expected to improve late outcomes. ${ }^{19}$

In our study, prosthesis-patient mismatch and extent of preoperative LV hypertrophy were not found to be predictors of LV mass regression as a dichotomous variable. Poor hemodynamic function of the $\mathrm{AV}$ prosthesis might be expected to affect LV mass regression after AVR, but studies of this are conflicting. ${ }^{15-17,21,22}$ The differing results may be related, in part, to the outcome used, for example, absolute LV mass, change in LV mass, or regression of hypertrophy to normal LV mass. In our patients, complete LV mass regression (dichotomous variable) was not related to prosthesis-patient mismatch. The influence of residual obstruction to flow through the prosthesis is mitigated in this study of the Trifecta valve because few patients had severe prosthesis-patient mismatch, and the valve has good hemodynamic performance. Indeed, informal comparison suggests that transvalvular gradients are lower and orifice areas are greater with the Trifecta prosthesis versus other stented bioprostheses and newer valve models designed for rapid deployment. ${ }^{6,23-25}$

Severity of preoperative LV hypertrophy has been reported to be an important determinant of postoperative $\mathrm{LV}$ 
mass regression in multiple studies. ${ }^{16,17,22}$ These prior investigations differed from ours, however, by expressing LV mass regression as a continuous variable or using nonsex-based definitions of LV hypertrophy. In our patients, preoperative LV mass was positively correlated with absolute reduction in LV hypertrophy but not with complete LV mass regression.

\section{Study Limitations}

This is a multi-institutional study of patients undergoing AVR with the Trifecta prosthesis, and this analysis has several limitations. First, baseline echocardiograms were studies performed at hospital dismissal early after surgery. Evidence suggests that there may be a small degree of LV mass regression in the few days early after surgery before the postoperative study. ${ }^{26}$ Thus, our baseline measurements may slightly underestimate the overall degree of LV hypertrophy. Second, we did not have detailed information on dosage, duration of treatment, and compliance with beta-blockers and calcium-channel blockers prescribed at dismissal. Third, because this is a newer prosthesis, patient follow-up data are limited at the longer time points, as indicated by the numbers of patients at risk.

\section{CONCLUSIONS}

In this study of patients with LV hypertrophy undergoing AVR with the Trifecta bioprosthesis, most LV mass regression occurred within the first year after operation. Several variables were independently associated with complete mass regression, including male sex, lower preoperative systolic blood pressure, and postoperative treatment with beta-blockers and calcium-channel blockers. This highlights the importance of continued careful medical follow-up of patients undergoing AVR for aortic stenosis.

\section{References}

1. Blackstone EH, Cosgrove DM, Jamieson WR, Birkmeyer NJ, Lemmer JH Jr, Miller DC, et al. Prosthesis size and long-term survival after aortic valve replacement. J Thorac Cardiovasc Surg. 2003;126:783-96.

2. Tao K, Sakata R, Iguro Y, Ueno M, Tanaka Y, Otsuji Y, et al. Impact of valve prosthesis-patient mismatch on intermediate-term outcome and regression of left ventricular mass following aortic valve replacement with mechanical prosthesis. J Card Surg. 2007;22:486-92.

3. Suri RM, Zehr KJ, Sundt TM III, Dearani JA, Daly RC, Oh JK, et al. Left ventricular mass regression after porcine versus bovine aortic valve replacement: a randomized comparison. Ann Thorac Surg. 2009;88:1232-7.

4. Tasca G, Brunelli F, Cirillo M, Dalla Tomba M, Mhagna Z, Troice G, et al. Impact of the improvement of valve area achieved with aortic valve replacement on the regression of left ventricular hypertrophy in patients with pure aortic stenosis. Ann Thorac Surg. 2005;79:1291-6.

5. Wendt D, Thielmann M, Plicht B, Assmann J, Price V, Neuhauser M, et al. The new St Jude Trifecta versus Carpentier-Edwards Perimount Magna and Magna Ease aortic bioprosthesis: is there a hemodynamic superiority? J Thorac Cardiovasc Surg. 2014; 147:1553-60.

6. Bavaria JE, Desai ND, Cheung A, Petracek MR, Groh MA, Borger MA, et al. The St Jude Medical Trifecta aortic pericardial valve: results from a global, multicenter, prospective clinical study. J Thorac Cardiovasc Surg. 2014;147:590-7.

7. Park SH, Shub C, Nobrega TP, Bailey KR, Seward JB. Two-dimensional echocardiographic calculation of left ventricular mass as recommended by the
American Society of Echocardiography: correlation with autopsy and M-mode echocardiography. J Am Soc Echocardiogr. 1996;9:119-28.

8. Lang RM, Bierig M, Devereux RB, Flachskampf FA, Foster E, Pellikka PA, et al; American Society of Echocardiography's Nomenclature and Standards Committee; Task Force on Chamber Quantification; American College of Cardiology Echocardiography Committee; American Heart Association; European Association of Echocardiography, European Society of Cardiology. Recommendations for chamber quantification. Eur J Echocardiogr. 2006;7: 79-108.

9. Tomoeda H, Ueda T, Teshima H, Arinaga K, Tayama K, Fukunaga S, et al. Postoperative left ventricular mass regression after aortic valve replacement for aortic stenosis. Ann Thorac Surg. 2010;89:745-50.

10. Hall SA, Cigarroa CG, Marcoux L, Risser RC, Grayburn PA, Eichhorn EJ. Time course of improvement in left ventricular function, mass and geometry in patients with congestive heart failure treated with beta-adrenergic blockade. J Am Coll Cardiol. 1995;25:1154-61.

11. Reiken S, Wehrens XH, Vest JA, Barbone A, Klotz S, Mancini D, et al. Betablockers restore calcium release channel function and improve cardiac muscle performance in human heart failure. Circulation. 2003;107:2459-66.

12. Packer M. Calcium channel blockers in chronic heart failure: the risks of "physiologically rational" therapy. Circulation. 1990;82:2254-7.

13. Packer M, O'Connor CM, Ghali JK, Pressler ML, Carson PE, Belkin RN, et al; Prospective Randomized Amlodipine Survival Evaluation Study Group. Effect of amlodipine on morbidity and mortality in severe chronic heart failure. $N$ Engl J Med. 1996;335:1107-14

14. Packer M, Carson P, Elkayam U, Konstam MA, Moe G, O'Connor C, et al; PRAISE-2 Study Group. Effect of amlodipine on the survival of patients with severe chronic heart failure due to a nonischemic cardiomyopathy: results of the PRAISE-2 study (prospective randomized amlodipine survival evaluation 2). JACC Heart Fail. 2013;1:308-14.

15. Del Rizzo DF, Abdoh A, Cartier P, Doty D, Westaby S. Factors affecting left ventricular mass regression after aortic valve replacement with stentless valves. Semin Thorac Cardiovasc Surg. 1999;11(4 Suppl 1):114-20.

16. Hanayama N, Christakis GT, Mallidi HR, Rao V, Cohen G, Goldman BS, et al. Determinants of incomplete left ventricular mass regression following aortic valve replacement for aortic stenosis. J Card Surg. 2005;20:307-13.

17. Beach JM, Mihaljevic T, Rajeswaran J, Marwick T, Edwards ST, Nowicki ER, et al. Ventricular hypertrophy and left atrial dilatation persist and are associated with reduced survival after valve replacement for aortic stenosis. J Thorac Cardiovasc Surg. 2014;147:362-9.e8.

18. Mihaljevic T, Nowicki ER, Rajeswaran J, Blackstone EH, Lagazzi L, Thomas J, et al. Survival after valve replacement for aortic stenosis: implications for decision making. J Thorac Cardiovasc Surg. 2008;135:1270-8.

19. Gaudino M, Alessandrini F, Glieca F, Luciani N, Cellini C, Pragliola C, et al. Survival after aortic valve replacement for aortic stenosis: does left ventricular mass regression have a clinical correlate? Eur Heart J. 2005;26:51-7.

20. Taniguchi K, Takahashi T, Toda K, Matsue H, Shudo Y, Shintani H, et al. Left ventricular mass: impact on left ventricular contractile function and its reversibility in patients undergoing aortic valve replacement. Eur J Cardiothorac Surg. 2007;32:588-95.

21. Kato Y, Suehiro S, Shibata T, Sasaki Y, Hirai H. Impact of valve prosthesispatient mismatch on long-term survival and left ventricular mass regression after aortic valve replacement for aortic stenosis. J Card Surg. 2007;22:314-9.

22. Brown ML, Schaff HV, Suri RM, Li Z, Sundt TM, Dearani JA, et al. Regression in left ventricular mass after aortic valve replacement for chronic aortic regurgitation is unrelated to prosthetic valve size. J Thorac Cardiovasc Surg. 2011;142:e5-9.

23. Ugur M, Byrne JG, Bavaria JE, Cheung A, Petracek M, Groh MA, et al. Suture technique does not affect hemodynamic performance of the small supra-annular Trifecta bioprosthesis. J Thorac Cardiovasc Surg. 2014;148:1347-51.

24. Suri RM, Michelena HI, Burkhart HM, Greason KL, Daly RC, Dearani JA, et al. A prospective, randomized comparison of 3 contemporary bioprosthetic aortic valves: should hemodynamic performance influence device selection? J Thorac Cardiovasc Surg. 2012;144:1387-95.

25. Kocher AA, Laufer G, Haverich A, Shrestha M, Walther T, Misfeld M, et al. One-year outcomes of the Surgical Treatment of Aortic Stenosis With a Next Generation Surgical Aortic Valve (TRITON) trial: a prospective multicenter study of rapid-deployment aortic valve replacement with the Edwards Intuity Valve System. J Thorac Cardiovasc Surg. 2013;145:110-5.

26. Ahmad N, Shahbaz A, Ghaffar A, Tufail Z, Waheed A, Khan JS. Early left ventricular remodeling after aortic valve replacement. J Ayub Med Coll Abbottabad. 2007;19:10-4. 